\title{
Políticas e práticas de gestão de documentos eletrónicos na Administração: o que está mudando em Portugal ${ }^{5}$
}

\section{Pedro Penteado}

DireÇÃo-Geral do LiVRO, DOS ARQuivos E DAS BiblioteCAS

DireÇÃo DE SERVIÇOS DE ARQUIVÍSTICA E NORMALIZAÇÃo

\section{Resumen}

A comunicação começa por apresentar alguns elementos para a compreensão dos novos contextos para a gestão da informação arquivística na Administração eletrónica. De seguida fornece a perspetiva do organismo de coordenação da política arquivística portuguesa - a Direção-Geral do Livro, dos Arquivos e das Bibliotecas (doravante designado pela sigla DGLAB), sobre as boas práticas de gestão da informação nas entidades da Administração Pública. Nesse sentido, especifica a aposta da DGLAB na interoperabilidade semântica através de instrumentos e produtos específicos como o esquema Metainformação para a Interoperabilidade (MIP), a Macroestrutura Funcional (MEF), a Lista Consolidada de informação relativa a processos de negócio da Administração (LC), com vista à sua classificação e avaliação. Apresenta ainda a proposta da DGLAB para o uso de ferramentas transversais para a

5 A comunicação apresentada, em castelhano, nas XXIII Jornadas de Archivos Universitarios, intitulava-se "Políticas y prácticas de gestión de documentos electrónicos en la Administración: Lo que está cambiando en Portugal". 
classificação e avaliação da informação pública, como as que resultam do Projeto de Avaliação Suprainstitucional da Informação Arquivística (ASIA). Nesse sentido, aprofunda a visão da DGLAB sobre a utilização destes instrumentos nos contextos organizacionais e pluriorganizacionais (por exemplo, nas instituições de Ensino Superior), com vista à elaboração e aplicação de planos de classificação e tabelas de seleção. Especifica também a procura de soluções para o problema da preservação da informação digital, quer a que é produzida no contexto arquivístico da Administração, quer em outras comunidades de prática, através do desenvolvimento do projeto "Continuidade digital". Por último, especifica a política de gestão de documentos eletrónicos existente no país, identificando as suas fragilidades e o que está a ser desenvolvido para as ultrapassar.

Palabras clave: Administração Pública; Gestão de documentos eletrónicos; Interoperabilidade semântica; Política de informação; Portugal.

Cita recomendada: Penteado, P. (2018). Políticas e práticas de gestão de documentos eletrónicos na Administração: o que está mudando em Portugal. En El archivo electrónico en la administración digital: 23 Jornadas de Archivos Universitarios, 21-23 de junio de 2017, A Coruña (pp. 61-74).

DOI capítulo: https://doi.org/10.17979/spudc.9788497496803.061 DOI libro: https://doi.org/10.17979/spudc.9788497496803 


\section{Administração eletrónica: um novo contexto para a gestão da informação arquivística}

Nos últimos quinze anos têm-se acentuado a Administração eletrónica enquanto forma de impulsionar a comunicação entre os vários níveis de Administração Pública (AP) e os diferentes poderes públicos, bem como meio para conseguir oferecer aos cidadãos e às empresas melhores serviços, com mais qualidade, através da melhoria dos processos de trabalho e o uso das tecnologias da informação e comunicação (veja-se, por exemplo, Martínez Usero, 2007). Deste modo, a execução de políticas públicas pela Administração tem-se pautado pelo desenvolvimento de processos de trabalho cada vez mais otimizados e pelo recurso crescente a sistemas de informação integrados e plataformas informáticas que visam favorecer a gestão e a partilha de informação. $\mathrm{O}$ recurso a estas soluções tecnológicas é crítico, principalmente quando estas suportam processos transversais, em grande parte desmaterializados, que atravessam diferentes Administrações e organizações públicas que trabalham em rede na gestão supraorganizacional dos problemas ou casos colocados pelos cidadãos, obrigando ao uso de soluções de interoperabilidade e de reutilização dos dados e informação existentes nos repositórios da Administração, conforme as propostas de vários documentos de política europeia ${ }^{6}$. Neste sentido, a gestão pública obriga a requisitos cada vez mais exigentes no tratamento, preservação e exploração da informação arquivística eletrónica necessária, que se tem de manter utilizável, autêntica e confiável a longo prazo. Por outro lado, estes critérios devem ser definidos e implementados o mais cedo possível

\footnotetext{
${ }^{6}$ Veja-se, por exemplo, o "Plano de ação europeu (2016-2020) para a administração pública em linha. Acelerar a transformação digital da administração pública" COM(2016) 179 final ou a recente versão do "Quadro Europeu de Interoperabilidade - Estratégia de execução", com a publicação da $\operatorname{COM}(2017) 134$ final, ambas Comunicações da Comissão ao Parlamento Europeu, ao Conselho, ao Comité Económico e Social e ao Comité das Regiões.
} 
nas organizações, para o que estas devem ultrapassar as suas limitações estruturais e seguir boas práticas internacionais.

\section{Boas práticas de gestão da informação arquivística}

A gestão da informação arquivística ou gestão de documentos de arquivo, incluindo os de caráter eletrónico, depara, no caso da Administração Pública portuguesa, com obstáculos estruturais para uma rápida e eficaz implementação da mudança exigida pela Administração eletrónica. Alguns destes obstáculos foram identificados nos sucessivos diagnósticos que a DGLAB tem promovido sobre o tema (Penteado, 2015). De entre eles, salientamos: a) na maior parte das entidades, a ausência de formalização de políticas e responsabilidades sobre o respetivo sistema de arquivo; b) a escassa dotação de recursos humanos afetos aos sistemas de arquivo; e c) a não utilização de instrumentos para a gestão de documentos de arquivo, como planos de classificação e tabelas de seleção e planos de preservação digital na maior parte das entidades, favorecendo a acumulação documental.

\subsection{A aposta na interoperabilidade semântica}

Para fazer face aos problemas identificados, a DGLAB tem produzido e promovido um conjunto de normas, orientações e boas práticas de gestão de documentos. Entre elas figura, em primeiro lugar, as que visam promover a Administração eletrónica e a interoperabilidade semântica, em particular, e a construção de instrumentos que permitam o registo e a classificação funcional transversal. Merecem destaque: 
1) o esquema Metainformação para a Interoperabilidade (MIP) com um conjunto de 17 elementos de metainformação descritiva, alguns deles obrigatórios, para registo dos recursos/documentos eletrónicos, baseado em referenciais internacionais (exemplo: ISO 23081, Dublin Core, Moreq, etc). Entre os elementos obrigatórios consta a classificação;

2) a Macroestrutura Funcional (MEF) - representação conceptual de funções e subfunções desempenhadas por organizações do setor público, utilizada para atribuição de classes de $1 .^{\circ}$ e $2 .^{\circ}$ nível a documentos de arquivo.

A DGLAB viria a desenvolver posteriormente, num contexto colaborativo, o projeto de "Harmonização de classes de $3 .^{\circ}$ nível em planos de classificação conformes à MEF", integrando numa Lista Consolidada a informação relativa a processos de negócio da Administração. Para não desenvolver excessivamente o esquema classificativo, utilizou o conceito de mapa conceptual, que entre outros aspetos explicita e torna transparente, para cada classe, todos os critérios e raciocínios lógicos intermédios (entre os 2. ${ }^{\circ} \mathrm{s}$ e $3 .^{\circ} \mathrm{s}$ níveis) que conduziram às propostas apresentadas. Para garantir a normalização no uso deste referencial nos planos de classificação das entidades da AP, a DGLAB passou ter a responsabilidade de aprovar e publicitar a referida Lista Consolidada.

Para promover o MIP e a MEF, bem como para desenvolver documentos técnicos que aprofundem os níveis de interoperabilidade semântica alcançados, a DGLAB coordena o Programa de Administração Eletrónica e Interoperablidade Semântica (PAEIS), de adesão voluntária ${ }^{7}$.

\footnotetext{
${ }^{7}$ Veja-se informação complementar, sobre o PAEIS e os referenciais ou instrumentos citados e os seus pressupostos técnicos e metodológicos, em <http://arquivos.dglab.gov.pt /programas-e-projectos/modernizacao-administrativa/macroestrutura-funcional-mef $>$.
} 
2.2. O Projeto de Avaliação Suprainstitucional da Informação Arquivística (ASIA) e dinâmicas da sua implementação

Numa fase posterior, a partir de 2015, a DGLAB procurou, com a colaboração de centenas de entidades, avaliar a informação estruturada de acordo com a Lista Consolidada, procedendo aos ajustamentos necessários desta. Para o efeito, avançou com o Projeto de Avaliação Suprainstitucional da Informação Arquivística (ASIA), após definição da metodologia e dos instrumentos de recolha adequados. Neste projeto determinaram-se os prazos de conservação e destino final da informação pública, numa perspetiva transversal. Para os casos de processos de negócio com diferentes soluções de avaliação (por exemplo, com componentes de informação para eliminar e outras para conservar permanentemente, foram criados $4 .^{\circ} \mathrm{s}$ níveis de classificação). Os resultados do Projeto, de natureza incremental, foram incluídos na Lista Consolidada que, assim, passou a integrar também as decisões de avaliação para a informação constante nos processos de negócio da Administração ${ }^{8}$. Com este referencial disponível as entidades públicas podem agora, de modo facilitado, elaborar os seus projetos de elaboração e aplicação de planos de classificação e tabelas de seleção ${ }^{9}$, que podem ser de natureza organizacional ou supraorganizacional, por exemplo, ao nível de ministério/área governativa, da Administração Local ou de uma mesma tipologia (caso das instituições do Ensino Superior). A DGLAB fornece apoio técnico a estes projetos e formação específica, com prioridade para os provenientes de entidades aderentes do PAEIS. Têm

8 Sobre o assunto: <http://arquivos.dglab.gov.pt/programas-e-projectos/modernizacaoadministrativa/macroestrutura-funcional-mef/projeto-avaliacao-suprainstitucional-da-info rmacao-arquivistica-asia> e ainda <http://arquivos.dglab.gov.pt/wp-content/uploads/ sites/16/2017/08/FT2_LC.pdf>.

9 Atualmente a legislação obriga à publicação destas últimas em Portaria de gestão de documentos (PGD's).

66 
ainda procedido à elaboração de manuais de fichas técnicas de apoio à aplicação dos referenciais e instrumentos transversais.

No enquadramento atrás referido, destacamos o caso das instituições do Ensino Superior, que têm vindo a trabalhar com a DGLAB, nos últimos anos, com vista à construção do seu plano de classificação funcional e tabela de seleção, de uso transversal, e à avaliação da documentação acumulada, tendo criado o Projeto Comum de Gestão Documental nas Universidades Portuguesas (sobre este, veja-se Freitas, Corujo, e Sousa, 2015). Espera-se que o esforço desenvolvido permita ultrapassar os efeitos da falta de dinamismo da gestão de documentos na maior parte das instituições universitárias portuguesas, nas últimas décadas ${ }^{10}$.

\subsection{O projeto "Continuidade digital"}

Entre as boas práticas defendidas pela DGLAB para implementar nas entidades da Administração, incluindo as de caráter universitário, contam-se a aplicação de políticas, projetos e procedimentos de preservação digital. O tema, em geral, tem sido objeto de várias pesquisas e publicações com participação académica, salientando-se o trabalho de investigadores da Universidade do Minho (exemplo de Ferreira, 2006, e de Ferreira, Saraiva, e Rodrigues, 2012), da Universidade do Porto (Pinto, 2009), ou do Instituto Superior Técnico (IST), parceiro do projeto e$\mathrm{ARK}^{11}$.

${ }^{10}$ A gestão de documentos nas universidades, nos anos 90, foi objeto de trabalhos e intervenções pioneiras, particularmente devido ao esforço da equipa da Universidade do Porto e da Secção de arquivos universitários da BAD - Associação Portuguesa de Biliotecários, Arquivistas e Documentalistas (veja-se, por exemplo, Ribeiro, 1997). Em eventos públicos, o tema foi retomado, de modo mais visível, apenas em 2013, com o "Workshop - Arquivos Universitários", realizado em Lisboa pela FCSH-UNL, a 4 e 5 de Julho <https://workshoparquivosuniversitarios.wordpress.com>.

${ }^{11}$ Veja-se <http://www.eark-project.com>. 
A DGLAB há vários anos que tem procurado que as entidades da Administração Pública procedam, em primeiro lugar, à elaboração do seu Plano de preservação digital, que tornou obrigatório para todas as que pretendem salvaguardar informação com mais de sete anos de vida, independentemente do destino final. Para o efeito, produziu documento orientador $^{12}$.

Por outro lado, a DGLAB atuou também no desenvolvimento de um arquivo digital, originalmente criado com "capacidade de integrar, gerir e disseminar os objetos digitais produzidos na Administração Pública”, de acordo com a norma ISO 4721:2012 Space data and information transfer systems - Open archival information system (OAIS) - Reference model. Neste contexto, foi criado no final da década de 2000 o Repositório de Objetos Digitais Autênticos (RODA), que viria a ter de ser melhorado posteriormente (veja-se adiante a referência ao RODA +).

Por último, a DGLAB, com o desenvolvimento no Projeto "Continuidade digital", apostou na reunião de representantes de diversas comunidades de prática (exemplo: arquivos, bibliotecas, museus, setor dos audiovisuais e multimédia, jornalismo) com necessidades de gestão e preservação do património digital, com vista à exploração de soluções partilhadas e ao uso de recursos comuns. Procuraram analisar legislação, normas, terminologia, valores, boas práticas (incluindo a prévia avaliação da informação), bem como modelo de custos da preservação digital ${ }^{13}$, de modo a verificar as possibilidades de construção de uma rede comum de preservação de património digital, segundo um modelo distribuído. Entre as propostas a que chegaram encontra-se a constituição de uma rede cooperativa com serviços de armazenamento (quando os organismos

\footnotetext{
${ }^{12}$ Veja-se <http://arquivos.dglab.gov.pt/wp-content/uploads/sites/16/2014/02/Recomend producao_PPD_V2.1.pdf $>$.

${ }_{13}$ Mais informação disponível em <http://1 seminariopreservacaopatrimoniodigital.dglab. gov.pt/projeto-continuidade-digital/documentos-de-projeto>.
} 
aderentes não possuem essa capacidade), preservação, descrição complementar, pesquisa e recuperação de informação, certificação, formação, etc.

Mais recentemente, a DGLAB tem vindo a desenvolver o RODA + , atual plataforma tecnológica dedicada à preservação digital, baseado em tecnologias open source e incorporando, além do modelo OAIS, já referido, as normas EAD, METS e PREMIS, com soluções gizadas à luz de algumas das conclusões do projeto "Continuidade Digital" e orientada para servir a constituição da citada rede comum de preservação ${ }^{14}$.

\section{Que política de gestão de documentos eletrónicos?}

A maior parte das soluções defendidas ou implementadas pelo organismo de coordenação, ao nível da gestão de documentos eletrónicos na Administração, visa ultrapassar, através da adesão voluntária, de orientações e de boas práticas, um problema já há muito identificada no país: a insuficiência do quadro legal em vigor e a falta de políticas e instrumentos de gestão de documentos, particularmente no contexto da Administração eletrónica.

Já em 2012, a DGLAB, em conjunto com a Agência para a Modernização Administrativa (AMA), o IST e outras entidades, produziram um documento intitulado "Modelo de valorização da informação pública" que tinha como objetivo a elaboração de uma Recomendação do Conselho de Ministros (RCM) para aplicação obrigatória na Administração Pública, incluindo a Administração Local. Nele procuraram definir requisitos obrigatórios para qualificar sistemas de arquivo, incluindo os seus sistemas de gestão de documentos (record

\footnotetext{
${ }^{14}$ Cf.<https://roda.arquivos.pt $>$.
} 
systems), com base nas propostas das normas da família ISO 30300, ISO 15489 (em Portugal, NP 4438), nos requisitos do Moreq 2010, etc. Nesse sentido, o documento procurava definir um modelo de governação dos sistemas de arquivo das entidades da AP e identificar responsabilidades na sua gestão, sobretudo dos dirigentes superiores. Incluía ainda os requisitos para uma boa gestão da informação ao nível da captura, registo e descrição, organização, avaliação, armazenamento, recuperação e comunicação, etc. Pressupunha a capacidade de implementar auditorias aos sistemas de arquivo das entidades públicas, a desenvolver pela DGLAB (função que já executa desde 2007). Pretendia obrigar as entidades da Administração, num determinado prazo, a atingir um patamar razoável de gestão de documentos, associado a um modelo de maturidade (exemplo: uso obrigatório do plano de classificação e da tabela de seleção, independentemente da necessidade de eliminar informação pública). Tinha também como pressuposto o uso do MIP e da MEF como forma de assegurar a interoperabilidade semântica. Previa ainda medidas de preservação digital obrigatórias em todas as entidades.

Esta proposta, apesar de nunca ter tido aprovação superior, mantém as bases de outras que mais recentemente têm vindo a ser apresentadas pela DGLAB. A RCM n. ${ }^{\circ} 51 / 2017$, conhecida por "Papel Zero", tem por objetivo a desmaterialização de processos, a promoção da adoção de sistemas de gestão documental eletrónica e a digitalização de documentos de arquivo. Esta RCM apontou um conjunto de medidas que, entre outros aspetos, se pretendem implementar na administração direta do Estado. Determinou que a Direção-Geral do Livro, dos Arquivos e das Bibliotecas (DGLAB), em articulação com a AMA e a Fundação para a Ciência e Tecnologia, apresentasse ao Governo um conjunto de linhas orientadoras para a revisão da legislação arquivística adaptadas "às necessidades decorrentes da desmaterialização de processos e de 
informação". Deveriam contemplar "a) Classificação, avaliação e seleção de informação, tendo em consideração, sempre que possível, os princípios de uma Macroestrutura Funcional (MEF) e a Avaliação SupraInstitucional na Administração (ASIA); b) Esquema de meta informação para a interoperabilidade semântica; c) Preservação do património e da informação digital; d) Aquisição e comunicação de informação integrante do património cultural, científico e tecnológico"; bem como "Mecanismos de monitorização e controlo"15. A proposta da DGLAB tem de efetuar o devido alinhamento com outros diplomas estruturantes, a exemplo da RCM n. ${ }^{\circ}$ 91/2012, que aprova o Regulamento Nacional de Interoperabilidade Digital (RNID), bem como com o Decreto-Lei n. $^{\circ}$ 73/2014, que aprova a plataforma interoperabilidade da Administração Pública (iAP) como meio preferencial de comunicação entre os serviços e organismos públicos. Note-se que no âmbito do projeto piloto desenvolvido em 2016, foi estabelecido o uso obrigatório do MIP e da MEF para a troca e partilha de documentos neste contexto, embora não exista ainda legislação que o obrigue.

Também no âmbito do Programa Simplex +, de simplificação administrativa, está prevista a implementação de uma medida ( . $^{\circ}$ 51) destinada a "utilizar instrumentos transversais de gestão da informação, que visam classificar e controlar os documentos produzidos e recebidos nos organismos públicos. Estes instrumentos serão disponibilizados por uma plataforma modular de serviços partilhados, passível de integração com os sistemas de informação existentes em qualquer organismo. A plataforma permite ainda desmaterializar os procedimentos, atualmente obrigatórios, para se poder eliminar documentação em papel no Estado" "16. A Medida n. ${ }^{\circ} 51$ foi objeto de uma candidatura a

\footnotetext{
${ }^{15}$ A proposta foi apresentada superiormente em meados de agosto de 2017, esperando-se que possa constituir a base de um diploma para a implementação de uma correta política de gestão de documentos eletrónicos na Administração.

${ }^{16}$ Veja-se <https://www.simplex.gov.pt/medidas>.
} 
financiamento comunitário, através do Portugal 2020 / SAMA, com o projeto "Arquivo Digital: Plataforma modular para a classificação e a avaliação da informação pública", devendo a referida plataforma estar disponível em breve. Está previsto, neste contexto, o desenvolvimento de um diploma legislativo, ainda este ano, para suportar a implementação da referida plataforma e a gestão transversal da informação na Administração. Admite-se o cenário das tabelas de seleção terem um processo de aprovação menos complexo e mais célere que as atuais Portarias de gestão de documentos, podendo ser elaboradas através da extração dos resultados da avaliação aplicáveis a cada organismo a partir da Lista Consolidada, via plataforma.

\section{Conclusão}

Apesar dos problemas identificados na gestão de documentos eletrónicos em Portugal, o organismo de coordenação da política arquivística tem procurado implementar propostas para os ultrapassar, entre as quais se salientam os referenciais que permitem a interoperabilidade semântica e o registo e a classificação de documentos (MIP, MEF), bem como a avaliação supraorganizacional da informação pública. Nesse sentido disponibilizou recentemente a nova versão da Lista Consolidada, a partir da qual as entidades podem agora produzir de modo fácil e económico os seus planos de classificação e tabelas de seleção, com o apoio da DGLAB.

Ao mesmo tempo, este organismo procura aproveitar as oportunidades fornecidas pelas políticas de modernização administrativa e, em particular, de desmaterialização, como a Resolução do Conselho de Ministros n. ${ }^{\circ}$ 51/2017, conhecida por "Papel Zero", para efetuar propostas 
de revisão legislativa que permitam atualizar o modo como se efetua a gestão de documentos eletrónicos no país. O objetivo é permitir que o país possa dispor de políticas e soluções inovadoras para a gestão da informação que estejam suficientemente adequadas à nova administração em rede e a um modelo de gestão pública supraorganizacional.

\section{Bibliografía}

Ferreira, M. (2006). Introducão à preservação digital - Conceitos, estratégias e actuais consensos. Guimarães: Universidade do Minho. Recuperado de <https://repositorium.sdum.uminho.pt/bitstream/1822/5820/1/livro.pdf〉.

Ferreira, M., Saraiva, R., e Rodrigues, E. (2012). Estado da arte em preservação digital. S.1.: RCAAP. Recuperado de <http://projecto.rcaap.pt/index.php/ lang-pt/consultar-recursos-de-apoio/remository?func=fileinfo\&id=351>.

Freitas, C., Corujo, L., e Sousa, D. (2015). Projeto comum de gestão documental nas universidades portuguesas: harmonização e estabilização do vocabulário. Em Ligar. Transformar. Criar. 12. ${ }^{\circ}$ Congresso Nacional BAD. Recuperado de <https://www.bad.pt/publicacoes/index.php/congressosbad/article/view/ 1441/pdf_62>.

Lourenço, A. e Penteado, P. (2016). Simplex +: o que precisamos para além da Medida 51?. Em Arquivos Municipais: o que há de novo?. 12. Encontro Nacional de Arquivos Municipais. Recuperado de <https://www.bad.pt/ publicacoes/index.php/arquivosmunicipais/article/view/1535/1465>.

Lourenço, A. e Penteado, P. (2016). Avaliação Suprainstitucional da Informação Arquivística (ASIA): documento metodológico. Lisboa: Direção-Geral do Livro, dos Arquivos e das Bibliotecas. Recuperado de <http://arquivos.dglab.gov.pt/wp-content/uploads/sites/16/2016/03/ASIA_Do c-metodologico2016-03-10.pdf>. 
Lourenço, A. e Penteado, P. (2015). A caminho da ASIA: Avaliação Suprainstitucional da Informação Arquivística Em Ligar. Transformar. Criar. 12. ${ }^{\circ}$ Congresso Nacional BAD. Recuperado de <https://www.bad.pt/ publicacoes/index.php/congressosbad/article/view/1458/pdf_90>.

Lourenço, A., Penteado, P. (2014). Una estrategia para mejorar el acceso y la reutilización de la información pública en Portugal: el papel de la interoperabilidad semántica. Em Girona 2014: Archivos e Industrias Culturales. Recuperado de <http://www.girona.cat/web/ica2014/ponents/ textos/id200.pdf>.

Penteado, P. (2015). Gestão de documentos de arquivo na administração pública em portugal: experiências e desafios. Acervo, 28(2), 121-133. Recuperado de $<$ http://revista.arquivonacional.gov.br/index.php/revistaacervo/article/view/6 $12>$.

Pinto, M. M. (2009). PRESERVMAP. Um roteiro da preservação na era digital. Porto: Afrontamento.

Ribeiro, F. (1997). Gestão da informação no sistema de arquivo da Universidade do Porto. Em Conferência sobre arquivos universitários (pp. 5-11). Recuperado de <http://ler.letras.up.pt/uploads/ficheiros/artigo5411.pdf>.

Martínez Usero, J. Á. (2007). La gestión del conocimiento en la Administración electrónica. Madrid: Arco.

Nota: Para o PAEIS, MIP, MEF, LC, veja-se o site da DGLAB, particularmente $<$ http://arquivos.dglab.gov.pt/programas-e-projectos/modernizacao-adminis trativa>. 